\title{
Correlations between Physico-chemical Characteristics of Lamb L. dorsi Muscle
}

\author{
A. ASGHAR* and N. T. M. YEATES \\ Department of Animal Production, Faculty of Rural Science, \\ New England University, Armidale, Australia
}

Received January 9, 1976

\begin{abstract}
Simple and partial correlations were computed among 23 physico-chemical characteristics of $L$. dorsi muscle from lambs. The object was to single out those correlations which are inherent in the muscle composition and those which are dependent on nutritional status and age of the lambs. A large number of simple correlations between different characteristics were found to be significant.

However, the partial correlations, adjusted for plane of nutrition and age, revealed only for a small number of significant relationships which were inherent in muscle composition.

Most of the correlations were spurious, in the sense, that they depended mainly on the plane of nutrition and age of the lambs.

The intensity of correlation improved between some muscle characteristics by eliminating the effect of plane of nutrition and age. This suggests that the variation in those characteristics was not only due to plane of nutrition and age but some third factor was also involved in affecting their relationships.
\end{abstract}

The physiology of muscle cells is affected by a number of factors which influence the metabolic equilibrium of the cell., ${ }^{12}$ Despite "general adaptation syndrome" which provides an affective mechanism for accomodating the impact of the stressors, ${ }^{3}$ ) the interactions of these factors do cause variation in the composition of muscle. ${ }^{4,5)}$ Nevertheless, if two muscle components occur in a constant ratio, the interpretation is that a correlation exists between the components and the mechanism by which they are synthesized in the cells. Apart from theoretical interest, the significant correlations among different characteristics, if present, are valuable for practical purposes. For example, they may provide a simple mean of calculating tediously determined constituents from easily measurable ones. Moreover, for the estimation of 'relative' influence of different components of muscle on quality of meat by multiple regression, the information about the interdepen-

* Present address: Department of Food Technology, University of Agriculture, Lyallpur, Pakistan. dence among the concerned characteristics would be essential to deal with the problem of multi-collinearity, otherwise useful results cannot be achieved. ${ }^{6}$ ?

From different reviews, ${ }^{7,8}$ it appears that many workers have attempted to associate physico-chemical aspects of muscle with quality traits of meat, yet information about correlations among the muscle characteristics is scanty. The object of this study was to examine the intensity of correlation between different physico-chemical characteristes of $L$. dorsi muscle from lambs. Particular emphasis has been given to distinguish those correlations, which are dependent on nutritional status and age of the lambs from those which are inherent in the muscle composition.

\section{EXPERIMENTAL}

Source of experimental data. Twenty five Dorset Horn x Poll Merino breeding lambs, all by one sire, were reared from birth under similar high plane conditions, on their mothers. After 8 weeks they were divided into five groups, by restricted random sampling on the 
Table I. Simple Correlations

\begin{tabular}{|c|c|c|c|c|c|c|c|c|c|c|}
\hline & 1 & 2 & 3 & 4 & 5 & 6 & 7 & 8 & 9 & 10 \\
\hline \multicolumn{11}{|l|}{$\begin{array}{l}\text { 1) Ultimate } \mathrm{pH} \\
\text { value }\end{array}$} \\
\hline $\begin{array}{l}\text { 2) Cationic } \\
\text { groups }^{a)}\end{array}$ & -0.230 & & & & & & & & & \\
\hline $\begin{array}{l}\text { 3) Anionic } \\
\text { groups }^{a)}\end{array}$ & -0.416 & 0.331 & & & & & & & & \\
\hline $\begin{array}{l}\text { 4) Rigidity index } \\
\left(\mathrm{cm}^{2}\right)\end{array}$ & -0.154 & -0.124 & -0.124 & & & & & & & \\
\hline 5) Shortening $\%$ & 0.116 & 0.152 & 0.381 & 0.554 & & & & & & \\
\hline 6) Free water \% & 0.561 & -0.515 & -0.528 & -0.412 & -0.213 & & & & & \\
\hline 7) Bound water $\%$ & -0.285 & 0.600 & 0.420 & 0.364 & 0.207 & $7-0.922$ & & & & \\
\hline 8) Total water $\%$ & 0.835 & -0.101 & -0.474 & -0.316 & -0.119 & 0.658 & -0.316 & & & \\
\hline 9) Ash \% & -0.222 & 0.501 & 0.427 & -0.234 & 0.101 & -0.363 & 0.328 & -0.249 & & \\
\hline 10) Lipid \% & -0.708 & -0.053 & 0.341 & 0.221 & 0.076 & $5-0.466$ & 0.145 & -0.866 & 0.232 & \\
\hline 11) Sarc & -0.690 & 0.089 & 0.402 & 0.458 & 0.216 & $5-0.545$ & 0.255 & -0.842 & 0.183 & 0.709 \\
\hline $\begin{array}{l}\text { 12) Myofil } \\
\text { protein }\end{array}$ & -0.904 & 0.033 & 0.225 & 0.384 & -0.015 & -0.500 & 0.204 & -0.841 & 0.119 & 0.763 \\
\hline $\begin{array}{l}\text { 13) Free amino acid } \\
\text { nitrogen }^{b>}\end{array}$ & -0.722 & 0.169 & 0.412 & 0.223 & 0.215 & -0.447 & 0.212 & -0.697 & 0.172 & 0.554 \\
\hline 14) Myoglobin \% & 0.026 & -0.291 & -0.239 & 0.264 & -0.084 & -0.065 & 0.008 & -0.124 & -0.462 & 0.126 \\
\hline $\begin{array}{l}\text { 15) Stroma \% } \\
\text { 16) Acid-soluble }\end{array}$ & 0.679 & 0.198 & -0.031 & -0.484 & 0.002 & 0.266 & -0.035 & 0.596 & 0.036 & -0.582 \\
\hline $\begin{array}{l}\text { fraction of } \\
\text { stroma } \% \\
\text { 17) Alkali-soluble }\end{array}$ & -0.147 & 0.258 & 0.132 & -0.658 & -0.473 & 0.135 & -0.167 & -0.004 & 0.075 & 0.028 \\
\hline $\begin{array}{l}\text { fraction of } \\
\text { stroma \% } \\
\text { 18) Alkali-insoluble }\end{array}$ & 0.487 & 0.291 & 0.131 & -0.454 & 0.059 & 0.108 & 0.085 & 0.440 & 0.125 & -0.440 \\
\hline $\begin{array}{l}\text { fraction of } \\
\text { stroma \% } \\
\text { 19) Swelling factor }\end{array}$ & 0.905 & -0.182 & -0.505 & -0.223 & -0.109 & 0.552 & -0.300 & 0.782 & -0.282 & -0.700 \\
\hline $\begin{array}{l}\text { 19) Swelling factor } \\
\text { of stroma } \\
\text { 20) Sarcoplasmic/ }\end{array}$ & -0.463 & 0.248 & -0.090 & -0.182 & -0.268 & -0.285 & 0.161 & -0.399 & 0.000 & 0.398 \\
\hline & -0.113 & & & & 0.475 & -0.326 & 0.187 & 0.429 & 0.176 & 0.317 \\
\hline $\begin{array}{l}\text { 21) Extra-/intra- } \\
\text { cellular protein } \\
\text { ratio }\end{array}$ & 0.784 & 0.096 & 0.141 & -0.488 & -0.026 & 0.400 & -0.123 & 0.755 & -0.044 & -0.693 \\
\hline $\begin{array}{l}\text { 22) Fibre diameter } \\
(\mu)\end{array}$ & -0.518 & -0.012 & 0.068 & 0.580 & 0.164 & 0.506 & 0.289 & -0.690 & 0.073 & 0.588 \\
\hline $\begin{array}{l}\text { 23) Sarcomere } \\
\text { length }(\mu)\end{array}$ & -0.673 & -0.017 & 0.042 & 0.447 & -0.119 & -0.547 & 0.382 & -0.606 & -0.162 & 0.374 \\
\hline
\end{tabular}

Significance level at $5 \%, 2 \%, 1 \%$ and $0.1 \%$ probabilities are $0.423,0.492,0.537$ and 0.652 respectively.

basis of body weight, sex, age and growth rate. The groups number were then assigned by complete randomization technique. The methods described by Pearson and Hartley') was followed to determine the appropriate number of lambs per group. At the age of nine weeks group I was slaughtered and other four groups were weaned. Group III and IV were put on an improved pasture (high plane of nutrition), while group II and $V$ received sub-maintenance feeding. At 14 weeks of age group II and III were slaughtered, while group $\mathrm{V}$ was put on the improved pasture with group IV until the former achieved about the same weight as those in group IV, at which time both groups were slaughtered (i.e. at about 25 weeks age). However, two lambs, one each from group II and V died during experimental period. The data from these lambs were not included in the study. ${ }^{5}$

The details of the sampling and protein fractionation procedure have been given by Asghar and Yeates. ${ }^{107}$ The methods of estimation for the remaining biophysical and microscopic characteristics of muscle have been reported in another paper. ${ }^{6}$ )

Statistical analysis. Simple (total) correlation between 23 physico-chemical charactertics of muscle were computed on the basis of data, ${ }^{b)}$ taken from 23 lambs, 
BETWEen MusCle Characteristics

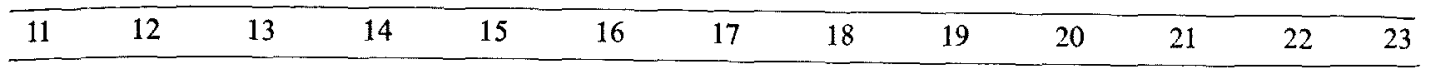

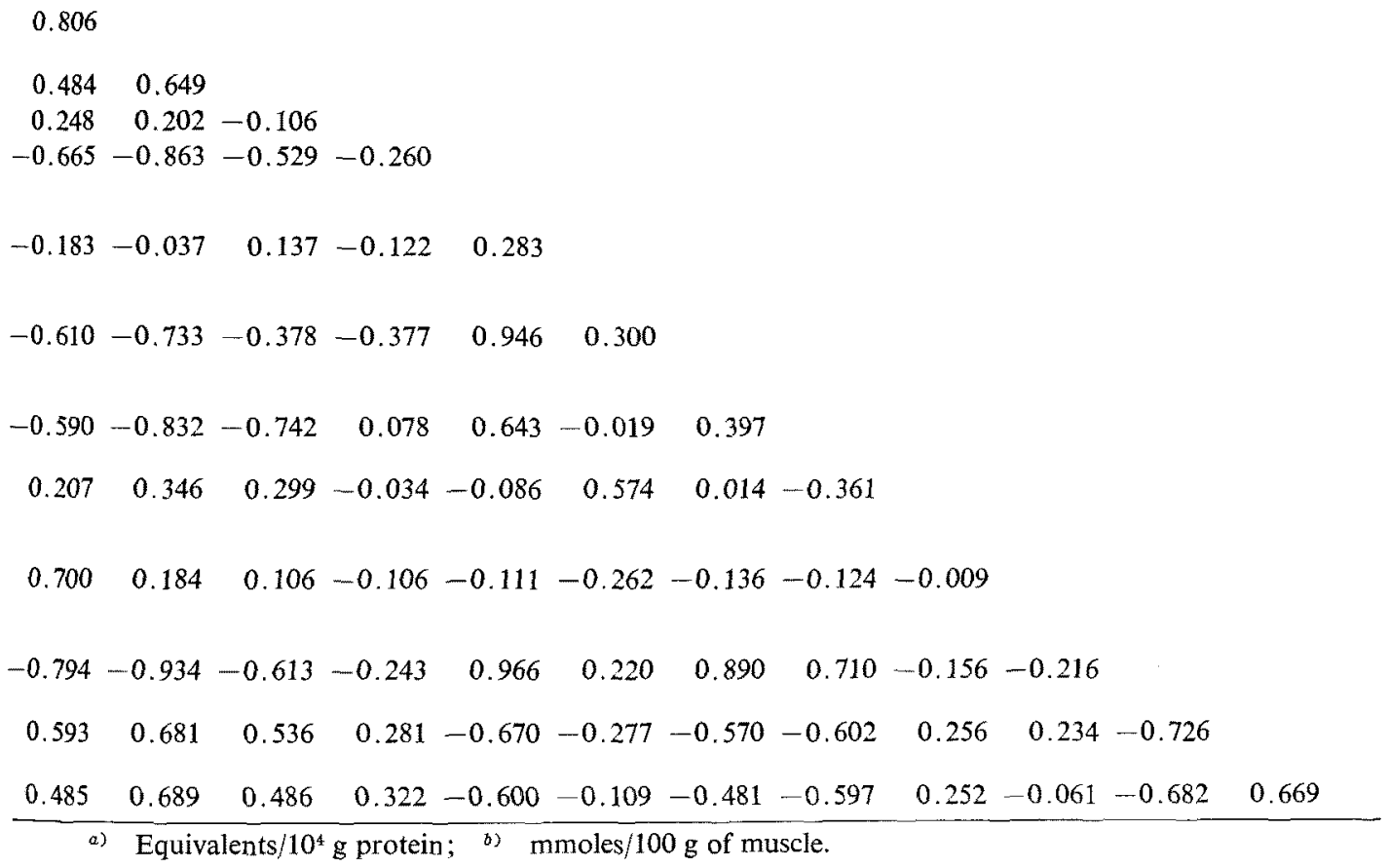

irrespective of the differences in the nutritional status and age of the lambs, whereas for the estimation of partial correlations between the muscle characteristics, the variations in plane of nutrition and the age factor were eliminated by holding them constant statistically. Standard methods ${ }^{11}$ ) for the computation of simple and partial correlation were followed, using Bar-3 Fortran programme ${ }^{12)}$ on computer IMB 1620 , Model 2.

\section{RESULTS}

The data in Tables I and II represent respec- tively the matrices of simple and partial correlation coefficients for 23 physico-chemical characteristics of $L$. dorsi muscle. It can be seen from Table I that a number of characteristics of muscle showed significant interdependence or covariance between them. But, when the results were compared with respective partial correlation coefficients (Table II), only the following relationships were found to be significant independent of plane of nutrition and age of the animals. For 
Table II. e) Partial Correlations

\begin{tabular}{lrrrrrrrrrr}
\hline & 1 & 2 & 3 & 4 & 5 & 6 & 7 & 8 & 9 & 10 \\
\hline & & & & & & & & & \\
1) Ultimate pH \\
value
\end{tabular}

example, the number of cationic group was positively related to 'bound' water $(r=0.607$, $\mathrm{P}<0.01)$ and negatively associated with free water $(r=-0.485, P<0.05)$. The 'free' water was directly correlated with total water $(r=$ $0.471, P<0.05)$. The sarcoplasmic and myofibrillar proteins were positively interrelated $(r=0.497, P<0.05)$ and the latter was inversely associated with the amount of stroma $(r=$ - 0.600, $P<0.01$ ), alkali-soluble stroma $(r=$ $-0.610, P<0.01)$ and with extra-/ intra-cellular protein ratio $(r=-0.770, P<0.001)$. There was direct relationship between total stroma and alkali-soluble stroma $(r=0.922, P<0.001)$.
The ultimate $\mathrm{pH}$ value was negatively correlated to myofibrillar protein $(r=-0.823$, $P<0.001)$ and positively to stroma $(r=0.577$, $P<0.01)$ alkali-soluble stroma $(r=0.481, P<$ $0.05)$, alkali-insoluble stroma $(r=0.548, P<$ $0.02)$ and extra-/ intra-cellular proteins ratio $(r=0.700, P<0.001)$. Total water percentage was negatively related to lipid ( $r=-0.655, P<$ $0.01)$, sarcoplasmic $(r=-0.758, \quad P<0.001)$ and myofibrillar proteins $(r=-0.470, P<$ $0.05)$, and to their ratio $(r=-0.520, P<0.05)$. The alkali-soluble stroma was positively related to extra-/ intra-cellular protein ratio $(r=0.876, \quad P<0.001)$. In all these cases 
between Muscle Characteristics

\begin{tabular}{|c|c|c|c|c|c|c|c|c|c|c|c|c|}
\hline 11 & 12 & 13 & 14 & 15 & 16 & 17 & 18 & 19 & 20 & 21 & 22 & 23 \\
\hline
\end{tabular}

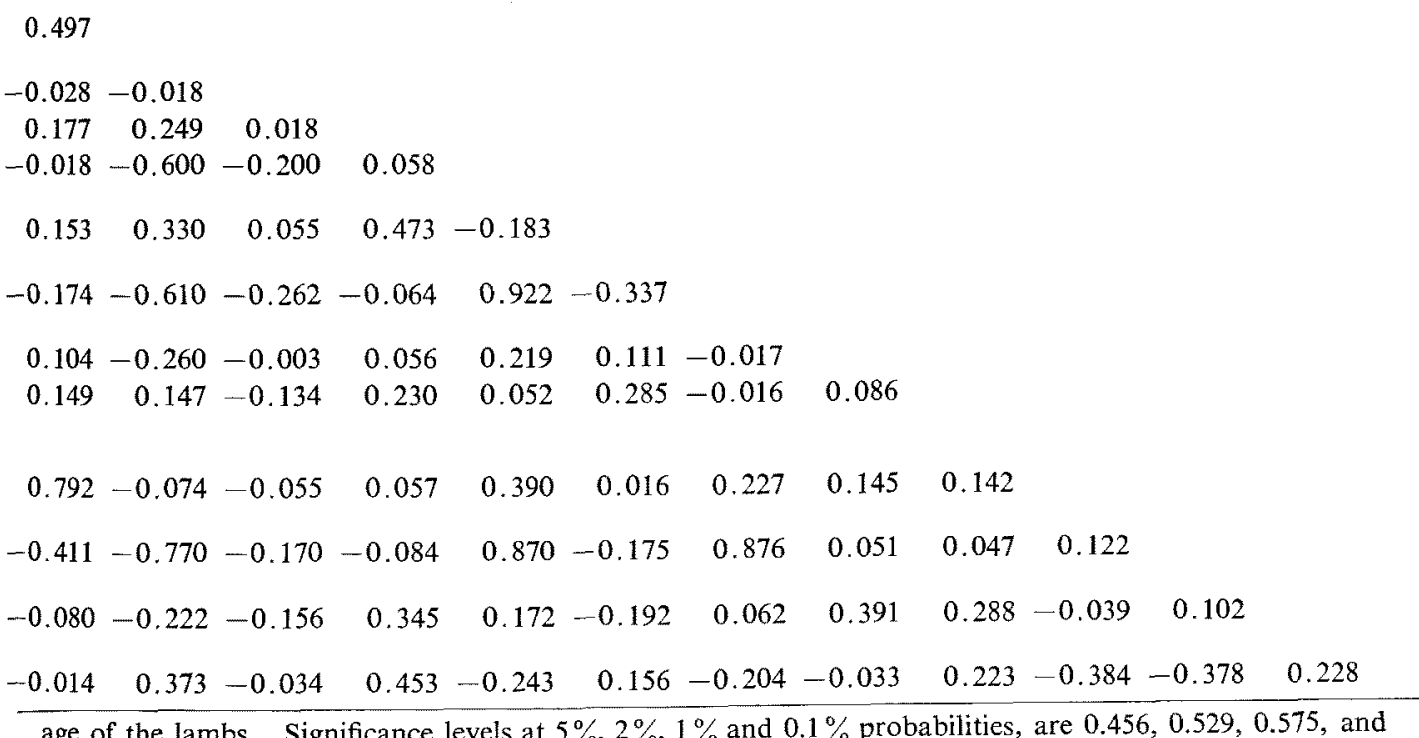

age of the lambs. Significance levels at $5 \%, 2 \%, 1 \%$ and $0.1 \%$ probabilities, are $0.456,0.529,0.575$, and

partial correlation coefficients (Table II) were significant, although the values were slightly lower than the simple or total correlation coefficients (Table I). This suggests that part of the relationship in these cases depended on nutritional status and age of the animal, but most of it was inherent in the muscle com. position.

On the other hand, elimination of the effect of nutrition and age, by holding them constant during partial correlation analysis, improved the intensity of correlation between 'rigidity index' and 'bound' water $(r=0.462$, $P<0.05$ ), shortening percentage and ultimate
$\mathrm{pH}$ value $(r=0.483, P<0.05)$, and between myoglobin and acid-soluble stroma $(r=0.473$, $P<0.05)$. Similarly, the shortening percentage showed significant inverse correlation with myofibrillar protein $(r=-0.481, P<0.05)$ and sarcomere length $(r=-0.517, P<0.05)$, while positive relationship with stroma $(r=$ $0.567, P<0.02)$, alkali-soluble stroma $(r=$ $0.545, P<0.02)$ and extra- $/$ intra-cellular protein ratio $(r=0.533, P<0.02)$. The number of anionic group showed negative correlation with fibre diameter $(r=-0.488, P<0.05)$ and sarcomere length $(r=-0.462, P<0.05)$, whereas the latter indicated inverse association with 
ash percentage $(r=-0.504, P<0.05)$.

It may be noted that the simple correlations in Table I for all these cases were not significant. This means that the variation in these variables was not only due to nutrition and age, but a third factor was also involved. When the plane of nutrition and age were kept constant, the relative correlating influence of the third factor enhanced, because a larger proportion of the variation in the concerned characteristics could now be attributed to the third factor. An other noticeable relationship was the simple correlation between anionic group and sarcoplasmic/myofibrillar protein ratio which differed significantly from zero $(r=0.505, P<$ 0.05 ), while their partial correlation coefficient still more so $(r=0.565, P<0.02)$. This suggests that a correlation, existing between plane of nutrition or age and these variables tended to reduce and to that extent falsify the apparent association between the concerned characteristics.

Apart from the above significant correlations, Table I shows a number of other simple correlations which were significant at or below $5 \%$ probability. However, the values of partial correlation coefficients for the same variables in Table II are not apparant $(P>$ 0.05). For example, in Table $I$ the number of anionic groups was found to be significantly associated with the percentage of 'free' and total water $(r=-0.528,-0.474, P<0.05)$. But, the partial correlation coefficients for the same variables in Table II were non-significant $(r=-0.034,-0.237, P>0.05)$. A number of similar cases can be seen in the table. All such significant correlations in Table I may be regarded as spurious because when the effect of nutrition and age of the lambs was eliminated, the partial correlations (Table II) of those variables approached zero, indicating that all those simple correlations were largely a reflection of close association of the concerned characteristics with the plane of nutrition and age of the lambs.

\section{DISCUSSION}

Some meat scientists have reported signi- ficant simple correlation between various physico-chemical aspects of muscle of meat animals. The present study provides a number of new correlations between muscle characteristics and also substantiates some of the earlier findings. However, disagreement did exist in certain cases, For example, some workers ${ }^{13 \sim 16\}}$ had recorded significant inverse association between water-holding capacity (free water) and $\mathrm{pH}$ value of muscle; theoretically, this seems to be a more logical relationship. Contrary to this, the simple correlation for these variables was found to be positive in the present study, while the partial correlation in Table II indicated that this relationship was not independent but was influenced by nutritional status of the animals. Possibly, the muscle components such as lipid and glycogen content which directly or indirectly have bearing upon the free water content and $\mathrm{pH}$ value of muscle, are affected by nutritional stress. ${ }^{5}$ Recently, Asghar and Yeates ${ }^{6}$ ) have provided evidence to show that the form and significance of the functional relationship between some muscle components are likely to be influenced by variation in other physico-chemical aspects of the muscle.

Wismer-Pedersen ${ }^{16)}$ and $\mathrm{Hamm}^{17)}$ found negative correlation between protein and free water content. Others also noted significant inverse association of free water (expressible juice) with sarcoplasmic protein. ${ }^{18)}$ Hegarty et $a l^{201}$ reported similar relation between free water and myofibrillar protein. The simple correlation data in the present study agree with most of these findings, however, partial correlations suggest that only sarcoplasmic protein exhibited some independent relation with free water $(0.1>P>0.05)$, while the other relationships were not inherent. Sayre and Birskey ${ }^{18)}$ also observed positive relationship of ultimate $\mathrm{pH}$ with sarcoplasmic protein, and to some extent with myofibrillar protein in contrast to negative correlation in the present study. But, in these cases too, only myofibrillar protein showed inverse association with ultimate $\mathrm{pH}$ value independent of nutritinnal status and aoe of the lambe whereas the 
relationship between sarcoplasmic protein and $\mathrm{pH}$ value appeared to be spurious.

Kauffman et $a l .{ }^{21)}$ reported negative correlation between alkali-soluble and alkaliinsoluble stroma. These results were again at variance with the present study. They have also found that acid-soluble stroma decreased with the age of the animal and the change was independent of the other fractions of stroma. In view of these observations, they implied that alkali-insoluble collagen is either precursor or the product of alkali-soluble fraction. However, such inferences can hardly be derived from correlation study. Simpson et al. ${ }^{22)}$ have emphasised that correlation tests only indicate whether or not any two variables in a given sample vary in such a way as to maintain a definite relation to each other. They tell nothing about the cause of the relationship but reveal its existence or lack of reliable evidence for it. Hence, there is a risk in passing from these numerical results to biological conclusions that the relationship may be misunderstood or may, without due consideration, be assumed to represent cause and effect. Anyway, according to the latest view about the biosynthesis of collagen in situ, the alkalisoluble fraction of stroma is now believed to be an intermediate product in the formation of alkali-insoluble stroma. ${ }^{23)}$ If it is so, then these fractions may hold a constant ratio but they may not necessarily maintain an inverse relationship with each other.

Ritchey $^{24)}$ derived significant negative correlation of fat content with free and total water (expect bound water) in $L$. dorsi muscle. Similarly, Carpenter and $\mathrm{King}^{25 /}$ found inverse relationship between fat and total water percentage, but Walter et al., ${ }^{15)}$ did not observe any association of total water or fat content with water-holding capacity (free water) or $\mathrm{pH}$ value. Apparently, the data in Table I support Ritchey's findings, ${ }^{24)}$ but partial correlation coefficients in Table II reveal that only total water had an inherent association with fat content, while other correlations were not independent of nutritional status and age of the lambs. The positive relation between fibre diameter and sarcomere length in the present study was also at variance with that of Herring et al., ${ }^{26)}$ who found linear negative correlation. In a subsequent study, they ${ }^{27}$ reported curvilinear relationship between these variables, which varied from seconddegree to fourth-degree curve, depending on the maturity of the cattle. This discrepancy may be due to the fact that their findings referred to muscle which was artificially stretched to various degrees.

Acknowledgement. The authors wish to thank Professor E.J. Burr for his advice in the statistical analysis of the data and to Professor M. A. Beg for critically going through the manuscript.

\section{REFERENCES}

1) H. H. Mitchell, "Comparative Nutrition of Man and Domestic Animals," Vol. 1, Academic Press, New York, 1964, p. 57, 133, 177.

2) R. W. Swift and K. H. Fischer, in "Nutrition- a comprehensive treatise," Vol. 1, eds. by G. G. Beaton and E. W. MeHenry, Academic Press, New Youk, 1964, p. 181.

3) R. A. Lawrie, in "The Physiology and Biochemistry of Muscle as Food," Vol. 1, eds. by E. J. Briskey, R. G. Cassens and J. C. Trautman, University of Wisconsin Press, Madison, 1966, p. 137.

4) H. N. Munro, in "Mammalian Protein Metabolism," Vol. 1, eds. by H. N. Munro and J. B. Allison, Academic Press, New York, 1964, p. 381.

5) A. Asghar, Ph. D. Thesis, University of New England, Armidale, Australia (1969).

6) A. Asghar and N. T. M. Yeates, J. Sci. Food Agric., 27 (11), (1976).

7) A. S. Szczesniak and K. W. Torgeson, Adv. Food Res., 14, 33 (1965).

8) M. E. Dikeman, Diss. Inst. B., 31, 6674 (1971).

9) E.S. Pearson and H. O. Hartley, "Biometrika Table for Statisticians," Vol. 1, Cambridge University Press, 1962, p. 25.

10) A. Asghar and N. T. M. Yeates, Agr. Biol. Chem., 38, 1851 (1974).

11) R. R. Sokal and F. J. Rohlf, "Biometry-the principles and practice of statistics in biological research," W. H. Freeman and Co., San Francisco, 1969.

12) E. J. Burr, "Bar- 3 User's Mannual," University of New England, Armidale, Austualia, 1968.

13) E. Wierbichi and F. E. Deatherage, J. Agric. Food Chem., 6, 387 (1958). 
14) R. Hamm, Z. Lebensm.- Unters. U. Forsch., 109, 227 (1959).

15) M. J. Walter, D. E. Goll, E. A. Kline, L. P. Anderson and A. F. Carlin, Food Technol., 19(5), 195 (1965).

16) J. Wismer-Pedersen, Food Res., 24, 711 (1959).

17) R. Hamm, Fleischwirtschaft, 14, 678 (1962).

18) R. N. Sayre and E. J. Briskey, J. Food Sci., 28, 675 (1963).

19) M. B. Webb, O. J. Kahlenberg, H. D. Neumann and H. B. Hedrick, ibid., 32, 1 (1967).

20) G. R. Hegarty, L. J. Bratzler and E. M. Pearson, ibid., 28, 525 (1965).

21) R. G. Kauffman, Z. L. Carpenter, R. W. Bray and W. G. Hoekstra, J. Agric. Food Chem., 12 (6), 604 (1964).
22) G. G. Simpson, A. Roe and R. C. Lewontin, "Quantitative Zoology," Harcout, Brace, New York, 1960.

23) K. A. Piez, in "The Physionogy and Biochemistry of Muscle as Food," Vol. 1, eds. by E. J. Briskey, R. G. Cassens and J. C. Trautman, University of Wisconsin Press, Madison, Wisconsin, 1966, p. 315.

24) S. J. Ritchey, J. Food Sci., 30, 375 (1965).

25) Z. L. Carpenter and G. T. King, Food Technol, 19, (11), 102 (1965).

26) H. K. Herring, R. G. Cassens and E. J. Briskey, J. Food Sci., 30, 1048 (1965).

27) H. K. Herring, R. G. Cassens, G. G. Suess, V. H. Brungart and E. J. Briskey, ibid., 32, 317 (1967). 